Critical Thinking: An Applied Approach, 2nd ed.

\title{
Daniel Boone
}

Dubuque: Kendall/Hunt, 2001. Pp. ix, 1-215. Paper. ISBN 0-7872-8156-5. \$43.50US.

\section{Reviewed by John Hoaglund}

This textbook of ten chapters is designed for a one-semester college-level course with the goal of applying "critical thinking methods to real source materials." Instructors are advised to use it with a companion set of pro-con readings on some one topic of contemporary interest to students. Explanations of skills are brief and to the point, their use is well illustrated, and there is an abundance of exercises. I regard this learn-by-doing approach as a plus, as well the suitability of the material for cooperative learning in small groups.

What constitutes critical thinking for the author is expounded in Chapter 1 : it is a "self-critical searching for the most justified beliefs," making judgments about situations, problems, and disagreements, and in the process it "interprets clearly, analyzes, evaluates" and appropriately attends to assumptions. This conception is based on the consensus of the Delphi Project of Peter Facione in 1990, simplified somewhat for the benefit of students. The discussion is welcome for three reasons: students benefit from an overall conception of critical thinking; as a comparatively new subject an explanation is due, and other writers might conceive critical thinking differently. On the other hand it isn't clear how this conception relates to the topics treated. Of the remaining nine chapters, seven deal with the analysis and evaluation of arguments. It might help if students were told this, as well as how argument analysis relates to this concept of critical thinking.

Chapters 2 on formal logic, 4 on missing premises, and 5 on evaluating real arguments are identified by the author as the core of the book. Let's look briefly at the other chapters before turning to these. Chapter 3 presents an arrow diagramming technique similar to Stephen Thomas' where linked arguments contrast with convergent. Boone demonstrates how to apply it (p. 40f.) to a complex argument quoted verbatim, and provides four similar arguments for student exercises. But he drops this technique after Chapter 3 because it cannot reveal whether an argument "is valid or invalid". (p. 41)

Chapter 6 on definitions deals with ambiguity and vagueness, Chapter 8 statistical fallacies, Chapter 9 scientific reasoning, and Chapter 10 a variety of topics including critical writing. Chapter 7 on informal fallacies will interest readers of a journal where considerable research on these has first seen print. But I fear they may be disappointed. Boone nowhere refers to any of this research nor is it reflected in his account. He does, however, get some use of Grice's conversational maxims. His definition (p. 103) of informal fallacy is in my judgment faulty. Such fallacies do mimic valid reasoning and can deceive, but they do not necessarily contain false premises and this is not how they deceive us. The "ad" fallacies 
typically deceive us with true premises when we fail to note that these are not probatively relevant to the conclusion.

Returning now to the three chapters that must be taught, 2 devotes ample attention to premise and conclusion indicators, a must for anyone dealing with arguments in natural language. The formal logic comprises eight valid and four invalid argument forms of propositional logic, with conditional arguments predominant. This makes the distinction of necessary from sufficient conditions, as it relates to the conditional statement form, the more valuable. There are also four valid syllogistic forms and two related ones with individual variables as well as terms.

Instructors concerned about the amount of class time needed to teach tests of validity for the syllogism will be relieved to hear that Boone cuts the Gordian knot by not teaching any traditional tests of syllogistic validity at all. This means no Venn diagrams, and no cumbersome details about the forms such as figure and mood. The latter help determine which terms are distributed, enabling one to test with the commonly used four rules.

I was misled by a detail of the first syllogistic form in this chapter and will mention it to keep others from going astray.

\section{All A are B}

All $\mathrm{B}$ are $\mathrm{C}$

All $\mathrm{A}$ are $\mathrm{C}$

Because the eye recognizes the figure from the position of the middle terms, I mistook this for a Barbara in Figure IV. But Barbara in IV isn't a valid form: the subject term is distributed in the conclusion but not in the minor premise, a violation of Rule 2. A closer look revealed my error. This is not a Barbara in IV but in Figure I, a valid form; however the minor premise is written before the major, a practice followed by the author for all the syllogistic forms. Since teachers using this text may be familiar with syllogisms, we should be told about this departure from the usual treatment and what advantage it provides.

Students of the medieval Schoolmen who lacked the mental energy to deal with rules of the syllogism - Aristotle bequeathed two general rules and then specific ones for each of the three figures he recognized - identified valid forms by memorizing Latin doggerel. Boone's four valid first-figure forms are:

Barbara celarent darii ferioque prioris

For students using this text, the general notion of arguments having a logical form is more important than any specific form a given argument might have. An argument is tested for validity by recognizing its form, then substituting formally equivalent premises in an attempt to combine all true premises with a false conclusion. When this attempt succeeds, the argument form is invalid; when not, valid. This refutation by logical analogy is a decided advance over any memorization technique.

For this text formal validity is the most important feature of an argument. Students test for formal validity by substituting for variables, and since the form of each argument has to be discovered, a notation that distinguishes types of vari- 
ables would seem advisable. Boone uses capital letters A, B, and C both for the terms of syllogisms (All A are $\mathrm{C}$ ) and for simple sentences of propositional logic (If A, then B). And he does address the issue by (1) explaining that in one case the letter stands for a class, for a sentence in the other; and (2) using a lower case s for an individual variable ( $\mathrm{s}$ is a $\mathrm{C}$ ). But even experienced logicians reserve capitals ( $\mathrm{F}$, G) for predicate variables and (S, P, M) terms of syllogisms, lower cases ( $p, q, r)$ for propositional variables and $(x, y)$ for individual variables. If notational distinction is needed by logicians familiar with the forms, it would appear even more important for students learning them for the first time.

Chapter 4 is a valuable treatment of missing premises, urging us to make use of what is given, and not to supply premises that would weaken the argument (referred to as the Principle of Charity by many writers on informal logic). The goal of supplying premises until the argument fits a valid form is questionable, but we can let it pass since Boone makes little use of it.

Chapter 5, "Evaluating Real Arguments," may be the text's most original. It teaches the analysis (by summarizing parts) and evaluation of extended arguments, an endeavor pioneered by the late Howard Kahane in Chapter 6 of Logic and Contemporary Rhetoric (Belmont 1971). The current technique includes identifying conclusions by seeking indicator words, by asking what the writer is attempting to prove, or what he is urging us to do. The advice on identifying main premises is not quite as helpful. We should ignore minor details and rhetoric - this seems obvious to us but it probably isn't for many students. The challenge is to distinguish major details from minor, and substance from rhetoric, on both of which the text is less forthcoming.

"Real argument" used by Kahane or by Blair and Johnson usually means "argument quoted from its source." For Boone in Chapter 5 in seven of nine cases it means "argument paraphrased from its source and organized into premises and conclusion." Examples of arguments quoted entire for Chapter 5 are the Declaration of Independence and a substantial essay urging that the right of employers to electronically monitor (e.g. e-mail) employees should be limited. Both seem excellent choices. But another technique for identifying main premises - using paragraph (one main premise per paragraph) or section divisions as a guide - does not work especially well with them. Take the Declaration: if you count the long list of grievances as a separate paragraph, it has 6 . Boone (p. 64) identifies six main premises of its argument, four of which are stated in the second paragraph.

What help do we get from the valid logical forms of Chapter 2 in dealing with these real arguments? Apparently none at all. All of the examples and problems of that chapter were replete with the appropriate materials such as explicit antecedents and consequents in conditional statements. But none were quoted from sources, which suggests they were devised by the author to illustrate the logical forms. The Declaration contains no syllogisms and no conditional arguments, though one might conditionalize the "when a long train of abuses" of Paragraph 2 (Boone doesn't). Facing this issue Boone still holds that "logical connectedness of the premises" is the basis for logical support. Since there aren't any such valid forms of connectedness "we can also view them as sometimes being more like metaphors for 
the connections made in our critical reasoning." "In developing critical summaries of arguments, we are no longer going to be making the logical connections visibly obvious by using the Chapter 2 patterns." (p. 62)

In fact, formal features are not identified for any of the nine arguments treated in Chapter 5, so formal validity is not used at all in their analysis and evaluation. But if formal features are useless for analyzing real arguments, and the latter is our goal, why teach them in the first place? Boone's actual technique comprises assuming all premises are true, next seeking specific reasons why the conclusion might be false, then searching for implicit premises that might strengthen the argument, and finally summing up the verdict. The second and third aspects of this technique are commendable for locating the argument in what Ralph Johnson terms the "dialectical tier," the larger debate of which it forms a part. The critical thinker learns to search here for factors that would cast doubt on the conclusion, and this background allows the formulation of unstated premises that may be both needed and doubtful. Both are valuable for the potential to expose weakness in an argument.

But the technique as a whole is puzzling. Why test the reliability of implicit premises, which a writer may legitimately disavow, and not the reliability of the premises she has explicitly advanced in support of the conclusion? Emphasis on testing premises for reliability is an important factor distinguishing critical thinking and informal logic from formal logic. Boone seems to be caught unhappily between two methods here. In testing an argument for formal validity we assume the premises are true and seek factors that would make the conclusion false. If the argument permits all true premises and a false conclusion it is formally invalid (has an invalid form) and cannot establish its conclusion. But none of the nine arguments in Ch. 5 have forms, as Boone himself recognizes, so to query whether their forms are valid or invalid is like asking the man with no cash whether he is paying with bills or coins.

Overall this text is suspended unhelpfully between formal and informal methods without appearing fully aware of the difference between the two. It is difficult to see how instructors or students could benefit from its use.

John Hoaglund Department of Philosophy and Religious Studies Christopher Newport University Newport News, VA 23606 